\title{
Psychometric Validation and Prevalence of Compulsive Buying Behavior in an Emerging Economy
}

\author{
Moin Ahmad Moon ${ }^{\text {* }}$, Saman Attiq ${ }^{2}$
}

\begin{abstract}
Prevalence of compulsive buying varies to a great extent that may be attributed to conceptual, methodological, cultural, sample, unreliable cutoff criteria and demographic differences in scales that measure this harmful behavior. This study aims to validate the psychometric properties of two compulsive buying scales; The Clinical Screener (TCS) and Compulsive Buying Index (CBI) develop a universal consumer classification criterion. We collected data from systematically selected 2820 shopping mall consumers and 895 university students from Pakistan. We used exploratory factor analysis (EFA) for identifying new factor structures and confirmatory factor analysis (CFA) for validating factor structures. Revised-TCS yielded two dimensions; shopping anxiety and irresistible spending measured with five items. Whereas, Revised-CBI proved to be a four items unidimensional measure. Both scales exhibited satisfactory reliability and validity and correlated with their antecedents and consequences in theoretically predicted directions. About 29 to $33 \%$ of shopping mall consumers and 28 to 29 $\%$ of university students were classified as compulsive buyers with Revised-TCS and RevisedCBI respectively. Compulsive buying scales provide a better preview of the phenomenon when their theoretical, methodological and cultural differences are adjusted. This study measured the prevalence of compulsive buying with a new comprehensive universal classification continuum that categorizes consumers with respect to their level of compulsiveness. Revised scales and classification scheme will help psychologist, financial councilors and other practitioners to identify affected compulsive consumers on multiple levels. The study was limited to fashion clothing related products in shopping mall consumers and university students.
\end{abstract}

Keywords: Compulsive Buying Scales, Scale Validation, Shopping Malls, Emerging Economies, Prevalence, Students

\section{Introduction}

Shopping is an integral and necessary part of not only our everyday life but also our economy (Maraz et al., 2016). Shopping is no longer merely an act purchasing instead it has become a habit that may lead to a detrimental psychiatric problem known as compulsive buying behavior (McElroy et al., 1994; Black, Shaw, McCormick, Bayless, \& Allen, 2012). Compulsive buying behavior (CBB) is defined as "chronic and repetitive purchasing that becomes a primary response to negative events or

\footnotetext{
${ }^{1}$ Air University School of Management,Multan Campus/ Szabist Islamabad

${ }^{2}$ University of Wah Cantt Wah, Pakistan

*Corresponding Author: moin@aumc.edu.pk
}

This work is Licensed under a Creative Commons Attribution-Noncommercial 4.0 International License 
feelings" (Faber \& O'Guinn, 1992, p. 459). This behavior is characterized by lack of control over the urges to purchase repeatedly to calm mental unrest (Roberts, Manolis, \& Pulling, 2014) and also a loss of control over this purchasing behavior (Achtziger, Hubert, Kenning, Raab, \& Reisch, 2015). Although DMS-5 (American Psychological Association, 2013) does not recognize CBB as a distinct psychological disorder, it has severe harmful personal, social, legal and financial consequences (Black et al., 2012).

Despite these detrimental consequences, CBB is on the rise (Moon \& Attiq, 2018). The incidence of compulsive buying ranged between " $2 \%$ to $8 \% " 25$ years ago in the US (Faber \& O'Guinn 1992). However, recent estimates indicate an escalation in this phenomenon by up to $17 \%$ (Maccarrone-Eaglen \& Schofield, 2017). These estimates provide even disturbing figures when we see outside the US. For instance, in China 19\% (Guo \& Cai, 2011), 32\% in France (Lejoyeux et al. 2007) and 11.3\% in Brazil (Villella et al. 2011). These variations are due to the lack of validated scales of CBB in cultures and economies other than the US (Moon \& Attiq, 2018; Achtziger et al., 2015; Maraz et al., 2016; Maccarrone-Eaglen \& Schofield, 2017). Therefore, the primary purpose this study is to validate two most widely used scales of compulsive buying empirically; the clinical screener (TCS) (TCS; Faber \& O'Guinn, 1992) and compulsive buying index (CBI; Ridgway, Kukar-Kinney \& Monroe, 2008) in an emerging economy.

TCS is a self-reported seven items measure developed as a screener to identify compulsive buyers from the general population. Items included in TCS assess particular feelings, thoughts, and behaviors related to compulsive buying (Faber \& O'Guinn, 1992). Initially, the items converged to a single factor in a sample of 388 self-identified compulsive buyers and 292 general consumers suggesting unidimensionality of measure with high internal consistency (Cronbach' Alpha=0.95) (Faber \& O'Guinn, 1992). Using the cutoff point at two standard deviations (a screener level of $p=0.7$ ) above mean of the normal population, the clinical screener successfully classified $8.1 \%$ general population as compulsive buyers (Faber \& O'Guinn, 1992, p. 466). The authors went on to suggest to use a more conservative level of significance at $p=0.95$ and classified $1.8 \%$ of the general population as compulsive buyers.

$\mathrm{CBI}$ is a six items measure. IT incorporates both dimensions of impulse control disorder (ICD) and obsessive-compulsive disorder (OCD) measured with three items each (Ridgway et al., 2008). The initial pool of 121 items generated to tap both these dimensions of CBB was reduced to 15 items by three consumer behavior researchers and was further reduced to nine items in exploratory factor analysis (EFA). Confirmatory factor analysis (CFA) revealed the final six items of CBI loading on two dimensions with a sample of 352 undergraduate students. CBI, like (TCS) also uses a dichotomous categorization of compulsive buyers. Consumers achieving a total score > 25 or averaged above the midpoint of 4 were classified as compulsive buyers.

Despite the fact that most compulsive buying studies use these scale for measuring compulsive buying, they identify somewhat different cases of compulsive buying and estimated prevalence varies to a great extent (Maccarrone-Eaglen \& Schofield, 2017;

Sukkur IBA Journal of Management and Business - SIJMB | Volume 5 No. 2 July - December 2018 @ Sukkur IBA University 
Moon \& Attiq, 2018). Researchers still believe that these estimates do not represent the accurate picture of compulsive buying in the US in general and in other cultures and emerging economies in particular (Maraz et al., 2016, Neuner, Raab \& Reisch 2005).

These differences may be attributed to conceptual, methodological, cultural, sample and demographic differences and use of unreliable cutoff point to estimate prevalence (Maccarrone-Eaglen \&Schofield, 2017; Maraz et al., 2016, Neuner, Raab \& Reisch 2005). For instance, conceptually, TCS focuses on the impulse control side of compulsive disorder whereas, $\mathrm{CBI}$ incorporates both obsessive-compulsive and impulse control sides of CBB. TCS has culturally conflicting items such as "Made only the minimum payments on my credit cards." because credit card usage is not common in emerging countries when compared to developed economies (Tommasi \& Busonera, 2012). Both of these scales use arbitrary cutoff points and dichotomously classify consumers into compulsive or non-compulsive buyers (Ridgway et al., 2008; Moon \& Attiq, 2018). Recent developments in the field emphasize that there may be more than two levels of compulsiveness of consumers (Moon \& Attiq, 2018; Maraz et al., 2016). Therefore, these classifications of consumers are over or under classification.

TCS estimates lifetime prevalence, whereas CBI estimates current prevalence. The lifetime estimates tend to over-represent the phenomenon and identify older consumers as compared to the estimates calculated by current prevalence. Furthermore, various studies have found different factor structures for TCS and CBI (Horváth, Adigüzel \& Herk, 2013; Gallagher et al. 2017; Tommasi \& Busonera, 2012; Ridgway et al., 2008; Moon \& Attiq, 2018) than the original ones. Furthermore, CBI is mainly used in the online sample, whereas, TCS is used mainly to screen out compulsive buyers from the general population.

As a result of the above discussion, a critical issue in compulsive buying research concerns how to operationalize and measure this problem behavior in emerging economies. The limited understanding of this behavior in emerging economies can mainly be attributed to the unavailability of locally validated scales (Horváth, Adigüzel \& Herk, 2013; Maraz et al., 2016; Maccarrone-Eaglen \& Schofield, 2017). To report the local validity and overcome controversies mentioned above, this study aims at 1) testing and validating original TCS and CBI scales and their factor structures. If not validated, 2) identifying and validating new factor structures in the shopping mall and student samples 3) defining a new categorization scheme for estimating the prevalence of compulsive buying. This study contributes to our understanding of CBB by 1) providing revised and locally validated scales of $\mathrm{CBB}, 2$ ) examining the underlying mechanism of $\mathrm{CBB}$ in an emerging economy by examining the relationships between $\mathrm{CBB}$, its antecedents \& consequences and 3) providing the prevalence estimates of $\mathrm{CBB}$ in shopping mall consumers and university student sample in Pakistan for the first time. In the following section, we discuss the methodological, cultural and technical limitations and shortcomings of both these scales in detail and discuss the correlates of compulsive buying behavior to establish nomological validity.

Sukkur IBA Journal of Management and Business - SIJMB | Volume 5 No. 2 July - December 2018 @ Sukkur IBA University 


\section{The Clinical Screener (Faber \& O'Guinn, 1992)}

TCS has several limitations and has been criticized over the years. For instance, the sample size used in the development of this TCS was minimal. The major focus of TCS is on the impulse control disorder as four out of seven items $(1,2,3,4)$ address this dimension while ignoring obsessive-compulsive disorder dimension of this behavior (McElroy et al. 1994; Hollander \& Allen 2006). TCS also incorporates antecedents and consequences of behavior as part of the scale, which should not be included in the scale (Ridgeway et al., 2008). Some culturally conflicting items such as item three and five (See Table 1) may not be an accurate representation of the phenomenon because checks are an outdated method of payments and credit cards are country specific (Ridgway et al. 2008; Maraz et al., 2016; Maccarrone-Eaglen \& Schofield, 2017). TCS heavily depends upon income-related items (3, 4 and 7) Therefore, it does not screen higher income compulsive buyers from the general population (Roberts, Manolis, \& Pulling, 2014).

TCS presents a very narrow, limited and quite restricted scope of compulsive buying behavior as it can only screen severe cases of compulsive buying behavior (Ridgway et al., 2008; Edwards, 1993; Roberts, Manolis, \& Pulling, 2014). Many researchers (e.g. Maccarrone-Eaglen \&Schofield, 2017; Ridgway et al., 2008; Maraz et al., 2016) have raised concerns about the decision of the cutoff point where, if an individual achieves TCS score < -1.34 then he/she would be classified as a compulsive buyer. Although the decision for cutoff point was made utilizing the most rigorous and detailed analytical procedure, still it is an arbitrary cut off point, and it should be re-assessed in a more meaningful manner (Maccarrone-Eaglen \&Schofield, 2017; Edwards, 1993).

TCS measures past/lifetime prevalence of compulsive buying tendencies that are agedependent and does not portray the true picture of the prevalence at the given point of time (Maraz et al., 2016). TCS uses a dichotomous scheme of categorization of the consumers into non-compulsive and compulsive buyers. This dichotomous categorization may lead to misclassification of consumers with respect to their degree or level of compulsiveness (Edwards, 1993). Originally, TCS was a unidimensional measure, but evidence suggest that TSC yields more than one factor, particularly outside U.S (e.g., Ridgway et al., 2008: Kwak et al. 2003; Roberts \& Sepulveda, 1999). Therefore, we predominantly assume that TSC will not yield a single factor solution in cultures/countries other than the U.S.

Table 1: The Clinical Screener (Faber \& O'Guinn, 1992)

\begin{tabular}{|c|c|c|}
\hline $\begin{array}{l}\text { Code } \\
\text { s }\end{array}$ & Statements* & Modified Statements \\
\hline FO1 & $\begin{array}{l}\text { Bought things even though I couldn't } \\
\text { afford them. }\end{array}$ & 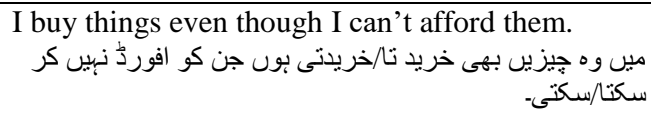 \\
\hline FO2 & $\begin{array}{l}\text { Felt others would be horrified if they } \\
\text { knew of my spending habits. }\end{array}$ & 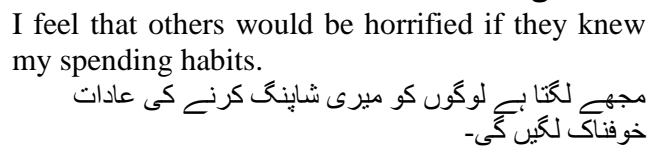 \\
\hline
\end{tabular}

Sukkur IBA Journal of Management and Business - SIJMB | Volume 5 No. 2 July - December 2018 @ Sukkur IBA University 
FO3 Wrote a check when I knew I didn't have enough money in the bank to cover it.

FO4 If I have any money left at the end of the pay period, I just have to spend it.

FO5 Made only the minimum payments on my credit cards.

FO6 Felt anxious or nervous on days I didn't go shopping.

FO7 Bought something in order to make myself feel better.

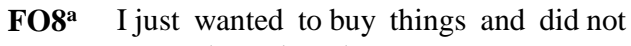
care what I bought

FO9 ${ }^{a}$ I really believe that having more money would solve most of my problem
I borrow money when I know that I don't have enough resources at my disposal.

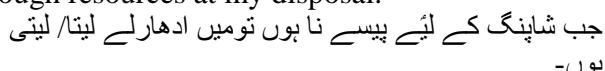

If I have any money left at the end of the month, I just have to spend it

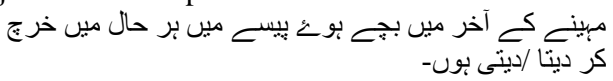

I buy excessively from my credit card but pay the minimum credit card bill to keep it running.

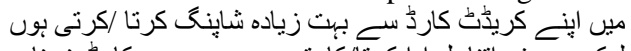

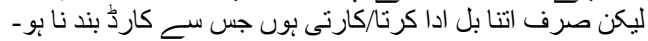

I feel anxious or nervous on days I don't go shopping.

جس دن ميس شاينَ كرنه نا جاؤن اس دن مضطرب يا بِريشان ربنا/ ربتى بون-

Sometimes I buy things to make me feel better.

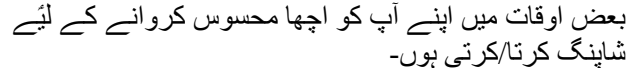

Sometimes, I just want to buy things and don't care what I buy.

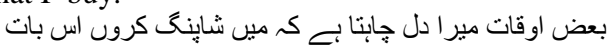

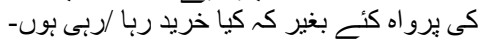

I really believe that having more money would solve most of my problems.

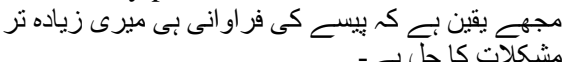

Notes: Items not included in the original 7 items final TCS.

*Original items

\section{Compulsive buying Index (Ridgway et al., 2008)}

The theoretical foundation of obsessive-compulsive spectrum disorder placed CBB farther from obsessive-compulsive disorder and nearer to impulse control disorder on the continuum (Hollander \& Allen 2006). CBI placed an equal emphasis on the obsessive-compulsive dimension in comparison to the previously acknowledged and dominant dimension of impulse buying (Edwards, 1993; Faber \& O'Guinn, 1992). Equal weighting of both dimensions may affect the results when it comes to the categorization and prevalence estimates. Although the cutoff point is carefully selected by comparing it to TCS, it is still an arbitrary decision at best (Maraz et al., 2016). CBI is majorly used to screen out online compulsive buyers. Its applicability to other consumer settings is scarce.

CBI only identifies two categories of consumers', i.e., compulsive or non-compulsive, while ignoring the presence of other levels of compulsiveness in individuals (Maccarrone-Eaglen \&Schofield, 2017; Edwards, 1993; Moon \& Attiq, 2018). The correlation found in three studies conducted by (Ridgway et al., 2008) between the two dimensions of compulsive buying index was 0.77 (in study 1), 0.60 (in study 2) and 0.72 (in study 3 ). This may imply that both obsessive-compulsive dimension and

Sukkur IBA Journal of Management and Business - SIJMB | Volume 5 No. 2 July - December 2018 @ Sukkur IBA University 
impulse buying dimension of CBI have negligible theoretical differences (Hair et al., 2013). Resultantly, CBI may provide a different factor structure than proposed originally.

Table 2: Compulsive Buying Index (Ridgway, Kukar-Kinney \& Monroe, 2008)

\begin{tabular}{|c|c|c|}
\hline Codes & Statements $^{\text {a }}$ & Modified Statements \\
\hline R1A* & $\begin{array}{l}\text { My closet has unopened shopping Bags in } \\
\text { it. }\end{array}$ & 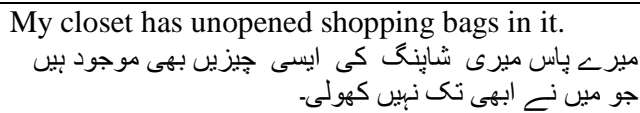 \\
\hline $\mathbf{R} 2 \mathbf{A}^{*}$ & Others might consider me a Shopaholic. & 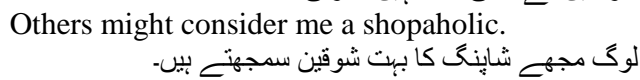 \\
\hline R3A & $\begin{array}{l}\text { I buy something for myself almost Every } \\
\text { day. }\end{array}$ & 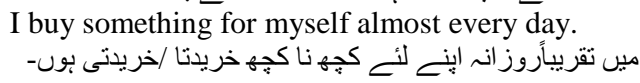 \\
\hline $\mathbf{R} 4 \mathbf{A}^{*}$ & $\begin{array}{l}\text { Much of my life centers around Buying } \\
\text { things. }\end{array}$ & 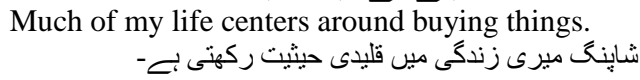 \\
\hline R5B* & I buy things I don't need & 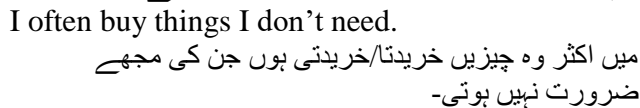 \\
\hline R6B* & I buy things I did not plan to buy & 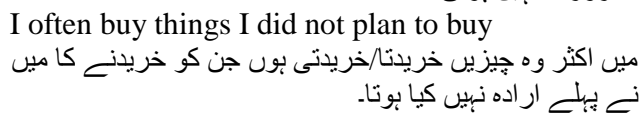 \\
\hline R7B & I buy things without thinking & I buy things without thinking. \\
\hline R8B & I am a bit reckless about what I buy & 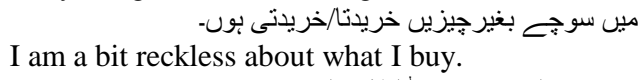 \\
\hline R9B* & I consider myself an impulse purchaser. & 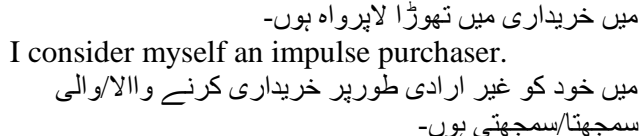 \\
\hline
\end{tabular}

Notes: Original items, * Items included in final CBI, $\mathrm{A}=$ Obsessive compulsive buying dimension, $\mathrm{B}=$ Impulse buying dimension

\section{Compulsive Buying Behavior Correlates}

To test the nomological validity of Revised-TCS and Revised-CBI, we examined the relationship between both scales of compulsive buying behavior, and it is theoretical correlates in university student sample (Sample B = 895). Compulsive buying is attributed to needless, uncontrollable and excessive shopping and this phenomenon is facilitated because of the introduction of shopping malls in emerging economies (Achtziger et al., 2015; Horváth, Adigüzel \& van Herk, 2013; Kukar-Kinney, Scheinbaum \& Schaefers, 2016). We included five antecedents of compulsive buying behavior in this study to test nomological validity. The first antecedent, depression is a severe medical illness that negatively affects how one feels, thinks and acts (McElroy et al., 1994). The second antecedent, anxiety is an internal state of distress and agitation (Bittner, Goodwin, Wittchen, Beesdo, Hofler \& Lieb, 2004). The third antecedent stress is any uncomfortable emotional experience accompanied by predictable biochemical, physiological and behavioral changes (Baum, 1990). Self-esteem is the fourth antecedent and is defined as "An individual set of thoughts and feelings about his or her

Sukkur IBA Journal of Management and Business - SIJMB | Volume 5 No. 2 July - December 2018 @ Sukkur IBA University 
worth and importance" (Rosenberg, 1965). Materialism, the fifth antecedent, is defined as the convictions of an individual that worldly possessions are the principal aim of life and a crucial course to identity, joy, and prosperity (Richins, 2004). Based on the previous findings, we hypothesized a positive relationship between depression, anxiety, stress, materialism and both scales (TCS and CBI) of compulsive buying behavior (Weinstein et al., 2016; ; Otero- Lopez \& Villardefrancos, 2013; Baker, Moschis, Rigdon \& Fatt, 2016; Moon \& Attiq, 2018; Maraz et al., 2016; Grougiou, Moschis \& Kapoutsis, 2015). A negative relationship between low self-esteem and compulsive buying was assumed based on previous research (Orth, Robins, Widaman, 2012; Ridgway et al., 2008; Moon \& Attiq, 2018).

Furthermore, we also included two consequences of compulsive buying behavior to test the external validity of both TCS and CBI. First consequence, positive feelings are defined as the momentary high that a compulsive buyer feels after buying compulsively (Moon \& Attiq, 2018; Ridgway et al., 2008). The second consequence is hiding behavior, which is defined as a compulsive consumer's tendency to hide his/her purchases from others due to anticipatory feelings of guilt, shame or remorse and criticism (Moon \& Attiq, 2018; Ridgway et al., 2008). Based on the previous findings, we assumed that both TCS and CBI would positively correlate with positive feelings and hiding behavior (Moon \& Attiq, 2018; Ridgway et al., 2008: Weinstein et al., 2016).

\section{Methodology}

\subsection{Sample}

Sample A consisted of 2820 (TCS $=1405, \mathrm{CBI}=1415$ ) systematically (every 5th) selected consumers entering the shopping mall (where clothing related products were available) in different cities of Pakistan. Sample B consisted of 895 systematically (every 5th) selected students from various universities of Pakistan who answered to TCS and CBI scales along with their various correlates. We used various guidelines for sample size selection. For instance, as a rule of thumb, the minimum sample size required for conducting an exploratory factor analysis (EFA) and structural equation modeling is 150 and 200 respondents respectively (Kline 2015; Hair et al., 2013). Hair et al. (2013) recommend that participant to observe variable ratio (1:5) to determine the minimum sample required. As a general rule of thumb for multivariate analysis, we require at least 300 respondents (Moon et al., 2018; Beavers et al., 2013). Previous researchers used maximum 1447 shopping mall consumers (Maraz et al., 2015) and 854 university students (Zhao, Tian \& Xin, 2017). The sample size in this study comfortably exceeds the required minimum thresholds.

\subsection{Measures}

TCS is a self-reported seven items scale (Faber \& O' Guinn, 1992). We made a few modifications in the TCS in line with the study objectives. First, to measure the current prevalence effectively, we transformed TCS items from past to present tense. Second, we measure all items on a five-point level of agreement Liker scale anchored at " 1 =

Sukkur IBA Journal of Management and Business - SIJMB | Volume 5 No. 2 July - December 2018 @ Sukkur IBA University 
strongly disagree/5 = strongly disagree". Third, we included two more items (Table 1: item 8 and 9) left initially because of their negative factor loads and positive bivariate correlations with other seven items (Faber \& O' Guinn, 1992). Fifth, we translated the original TCS into Urdu for administration. Three English and Urdu language experts translated and then back-translated the questions. Three consumer behavior experts then evaluated the items for context. In the end, two experts (authors) approved the final version.

CBI (Ridgway et al., 2008) is six items two-dimensional scale that measures the elements of compulsivity and impulsivity of compulsive buying behavior. We made a few technical changes in the original CBI. First, we included three items (item 3, 7 and 8) that Ridgway et al. (2008) excluded during CFA. Second, we employed a five-point level of agreement Likert scale that ranged from " $1=$ strongly disagree to $5=$ strongly agree". Third, we modified two items (items 4 and 5) so that they may be measured on the level of agreement. Fourth, we translated the items to Urdu following the same procedure outlined for TCS.

As correlates of CBB, we adopted nine items materialistic value scale (Richins, 2004), anchored at $1=$ strongly disagree and $5=$ strongly agree. We adopted Rosenberg's (1965) 10 items self-esteem scale, anchored from $1=$ strongly disagree to $4=$ strongly agree. The DASS-21 measures each depression, anxiety, and stress with seven items (Lovibond \& Lovibond, 1995). A severity scale of four points (at $0=$ "didn't apply to me at all" and 3 = "Applied to me very much or most of the time") measures the extent to which each state is experiencing over the past week. We measured hiding behavior, and positive feelings three items each developed by Ridgway et al. (2008) on a sevenpoint Likert scale anchored at $1=$ strongly disagree and $7=$ strongly disagree. We translated all these measures into Urdu following the procedure mentioned above for TCS and CBI.

\subsection{Data Collection}

\subsubsection{Sample A (Shopping Mall Consumers)}

We collected data from shopping mall consumers via mall intercept method from several shopping malls across the country between March and December 2017. We carefully selected shopping malls keeping in mind that the shopping mall must have clothing related assortment (Local and International brand representation) and healthy customer flow. Seven groups of 4 to 7 students, who were provided with the necessary training, collected the data against extra course credits during regular operating hours of shopping malls. TCS and CBI were administered in two separate survey questionnaires along with primary demographics characteristics that included gender, age, income and buying frequency. Overall, we contacted 25,190 individuals in shopping malls. Of whom 8,901 did not stop at all and 16,289 stopped and received study information. 8,238 agreed to participate in the study, of which 2,612 were excluded from the study because they were below 18 years. A total of 5,626 participants received the study questionnaire, and 1,112 did not return the questionnaire while

Sukkur IBA Journal of Management and Business - SIJMB | Volume 5 No. 2 July - December 2018 @ Sukkur IBA University 
another 756 started but did not complete. After removing responses that contained missing demographic information and unengaged responses, we were left with 2820 $(\mathrm{TCS}=1405, \mathrm{CBI}=1415)$ valid, usable surveys.

\subsection{2. $\quad$ Sample B (University Students)}

We collected data from different public and private universities of Pakistan between February and May 2017. Three groups of students ( 3 to 5 students), having completed their basic research course were assigned with this task against extra course credits. They collected data during the scheduled classes by systematically selecting students from the attendance register. The questionnaire included items of Revised-TCS and Revised-CBI along with the measures of materialism, self-esteem, depression, anxiety, stress, hiding behavior and positive. Initially, we contacted 3,145 students, but only 3004 agreed to participate in the study. 523 were dropped as these students were below the age of 18 years. In total 2,481 students were given questionnaires and only 1,539 completed and returned the questionnaire. After discarding unengaged responses and responses with too much missing information, we collected 895 valid usable responses.

\subsection{Data Analysis}

Before moving on to data analysis, we screened data for any misapplications. First, we removed cases with excessive missing values (Missing values $\geq 10 \%$ ) and imputed missing data points (Missing values $<10 \%$ ) via the mean substitution method (Gallagher et al. 2017). We identified univariate out liars with z-scores and multivariate outliers with Mahalanobis distance (d2) at $\mathrm{p}<0.05$ (Byrne, 2013). For assumptions of normality, we assessed skewness $( \pm 1)$ and kurtosis $( \pm 3)$ (Tabachnick \& Fidell, 2007). We tested multicollinearity between independent variables (Sample B $=895$ ) with variable inflation factor (VIF < 10) and tolerance level (> 0.1) (Hair et al., 2013).

To test and validate original factors structures of TCS and CBI, we performed confirmatory factor analysis (CFA) with robust Maximum Likelihood Estimation (MLE) (Hair et al., 2013; Kline, 2015). We used multiple model fitness indices to assess the goodness of fit (see Kline, 2015). Further, we assessed modification indices (M.I. < 10 ), standardized factor loadings ( $\mathrm{FL} \geq 0.7$ ), squared multiple correlations (SMCs $\geq$ 0.2 ) and standardized residual covariance (SRC $<2.58$ ) for all observed variables in the model (Byrne, 2013; Kline, 2015).

Where the original factor structure did not fit the data in CFA, we conducted Exploratory Factor Analysis (EFA) to explore new factor structures for TCS and CBI with Maximum Likelihood Estimation (MLE) and Oblique Promax-Rotation (Beavers et al., 2013; Tabachnick \& Fidell, 2007). To explore the new factor structures for TCS and CBI with sample A $(\mathrm{N}=2820)$, we divided Sample A into randomly selected two non-over lapping groups (Maraz et al., 2016). We used Sample A 1 (TCS; N=703: CBI; $\mathrm{N}=708$ ) to identify new factor structures in EFA and Sample A 2 (TCS; N=702: CBI; $\mathrm{N}=707$ ) to confirm factor structure in CFA. In EFA, results of Kaiser-Meyer-Olkin $(\mathrm{KMO} \geq 0.5)$ and Bartlett's test of Sphericity (App Chi-square at $\mathrm{p}<0.01)$ indicated the

Sukkur IBA Journal of Management and Business - SIJMB | Volume 5 No. 2 July - December 2018 @ Sukkur IBA University 
adequacy of sample size (Beavers et al., 2013; Leech, Barrett, \& Morgan, 2005). Communalities $\left(\mathrm{h}^{2} \geq 0.2\right)$ indicated a high correlation of an item with all other items (Henson \& Roberts, 2006; Childs, 2006). We made factor retention decision based on; Kaiser Criterion of Eigenvalues $>1$ (Costello \& Osborne, 2005), Cattell's scree test (Henson \& Roberts, 2006), factors explaining more than $50 \%$ of cumulative variance (Beavers et al., 2013), goodness of fit with Chi-Square and degree of freedom at $\mathrm{p}<$ 0.05 (Hair et al., 2013; Kline, 2015) and theoretically explainable factors (Suhr, 2006). While evaluating pattern matrix, first, we removed items with factor loadings $<0.4$ (Costello \& Osborne 2005). Second, items with significant factor loadings (FL $\geq 0.4$ ) on multiple factors were removed. Third, any significant loading on one factor had to be twice as much the loading on any other factor for a particular item. Fourth, items significantly loading on any factor must converge with other items on the factor (Tabachnick et al., 2007). We confirmed these new factor solutions in CFA based on previously described criteria.

To test the nomological/external validity of TCS and CBI, we conducted structural equation modeling (SEM) using two-step procedure outlined by (Anderson \& Gerbing, 1988) on a second independent sample (Sample $B=895$ ). To evaluate reliability and validity of the measures, we used Cronbach's Alpha $(\alpha \geq 0.7)$, Inter-construct correlations $(\mathrm{r} \leq 0.7)$, composite reliability $(\mathrm{CR} \geq 0.7)$ and average variance extracted (AVE $\geq 0.5$ ) (Hair et al., 2013; Fornell \& Larcker, 1987).

To overcome the shortcomings of cutoff points and classification schemes of TCS and CBI, we purpose a universal cutoff point that classifies consumers on a continuum (See Moon \& Attiq, 2018). Drawing on psychological object theory (Albanese, 1988) this continuum draws a parallel between compulsive and addictive buying to identify compulsive buyers with respect to varying levels of compulsiveness of consumers. We calculate respondent's mean score on the CBB scale and categorize consumers as noncompulsive/normal consumer $($ Mean= 1.0), recreational consumer $($ Mean= 1.1-2.0), borderline compulsive consumers $(\mathrm{Mean}=2.1-3.0)$, compulsive consumers ( $(\mathrm{Mean}=$ 3.1-4.0) and addictive consumers (Mean=4.1-5.0).

\section{Results and Analysis}

\subsection{Sample demographics}

Out of total 2820, shopping mall consumers (Sample A), $61 \%$ were male, and 39\% were female. Majority of the respondents (78\%) were between the ages of 18 to 28 years and the majority (57\%) had a monthly income up to PKR 50,000. Only $16 \%$ reported buying daily, whereas $29 \%$ and $55 \%$ reported buying weekly and monthly respectively. In Sample B $(\mathrm{N}=895), 51 \%$ of students were females, and $79 \%$ were of age between 18 to 26 years. They had an average monthly income, not more than PKR $30000(66 \%)$ and reported buying once a month (72\%), weekly (18\%) and daily (10\%).

Sukkur IBA Journal of Management and Business - SIJMB | Volume 5 No. 2 July - December 2018 @ Sukkur IBA University 


\subsection{Original Factor Structure Validation of TSC and CBI}

We conducted CFA on original seven items TCS $(\mathrm{N}=1405)$ to test original one factor solution. Goodness of fit results indicated a non-optimal model fit $(\mathrm{CMIN} / \mathrm{df}=5.24$, $\mathrm{GFI}=0.85, \mathrm{AGFI}=0.97, \mathrm{CFI}=0.95, \mathrm{IFI}=0.92, \mathrm{NFI}=0.91, \mathrm{TLI}=0.88, \mathrm{RMSEA}=0.06$, PClose $=0.007)$ where three items had poor factors loadings. Likewise, to test original two factor structure of CBI, we performed CFA on six items, loading on two dimensions (impulsive buying= 3 items, compulsive buying= 3 items) with Sample A $(\mathrm{N}=1415)$. Two factor solution did not produce an optimal fit $(\mathrm{CMIN} / \mathrm{Df}=6.64, \mathrm{GFI}=0.88$, AGFI= 0.96, $\mathrm{CFI}=0.97, \mathrm{IFI}=0.97, \mathrm{NFI}=0.96, \mathrm{TLI}=0.94, \mathrm{RMSEA}=0.07, \mathrm{PClose}=0.009)$ with two items loading significantly (M.I. > 10) on alternative dimensions. Based on CFA results, we decided to identify new factor structure for TCS and CBI. Further, the correlation between both dimensions $(\mathrm{r}=0.94)$ indicated that scale does not produce two theoretically distinct factors (Moon \& Attiq, 2018).

\subsection{Revised TCS and CBI: New Factor Structure}

We performed EFA on nine items of TCS on Sample A1 $(\mathrm{N}=703)$. We included two additional items along with seven original items because these seven items could not produce an explainable factor solution (Maraz et al., 2016; Moon \& Attiq, 2018).

Table 3: Inter-Item Correlations for TCS

\begin{tabular}{llllll}
\hline Items & FO2 & FO6 & FO8 & FO1 & FO3 \\
\hline FO2 & 1.00 & & & & \\
FO6 & $0.38^{* *}$ & 1.00 & & & \\
FO8 & $0.46^{* *}$ & $0.54^{* *}$ & 1.00 & 1.00 & \\
FO1 & $0.20^{* *}$ & $0.31^{* *}$ & $0.29^{* *}$ & $0.37^{* *}$ & 1.00 \\
FO3 & $0.18^{* *}$ & $0.16^{* *}$ & $0.19^{* *}$ & & \\
\hline
\end{tabular}

Notes: $* * \mathrm{p}<0.01$, Determinant $=.656$

Results of the goodness of fit statistics (Chisquare $=1.850, \mathrm{Df}=1, \mathrm{p}<0.01)$ in parallel analysis indicated that two-factor solution best represents the data, accounting for $57 \%$ accumulated variance with Eigenvalues $>1$. In Table 4, it is evident that all items load significantly on their respective factor and no cross-loadings exist. Factor 1 consists of three items, whereas factor two has two items. Inter-item correlations (Table 3) are significant for all items (Beavers et al., 2013). Two factors significantly correlate with each other with a moderate correlation coefficient $(\mathrm{r}=0.25, \mathrm{p}<0.01)$ indicating two distinct yet theoretically related factors (Gallagher et al. 2017). We labeled two factors as; Shopping Anxiety $(\alpha=0.79)$ and Irresistible Spending $(\alpha=0.71)$ respectively based on thematic interpretation. Shopping anxiety refers to the state of restlessness that is associated with shopping, and irresistible spending refers to the compulsion to spend on undesired things. The overall reliability for the scale as measured by Cronbach's alpha was 0.81 .

Table 4: Exploratory Factor Analysis (EFA), Confirmatory Factor Analysis (CFA), Reliability and Validity of TCS 


\begin{tabular}{|c|c|c|c|c|c|c|c|c|c|}
\hline \multirow[b]{2}{*}{$\begin{array}{l}\text { New } \\
\text { Item \# }\end{array}$} & \multirow[b]{2}{*}{$\begin{array}{c}\text { Original } \\
\text { Item \# }\end{array}$} & \multicolumn{3}{|c|}{ EFA } & \multirow[b]{2}{*}{$\begin{array}{l}\text { Item } \\
\text { Mean }\end{array}$} & \multirow[b]{2}{*}{$\begin{array}{l}\text { Corrected } \\
\text { Item-Total } \\
\text { Correlation }\end{array}$} & \multicolumn{3}{|c|}{ CFA } \\
\hline & & $\begin{array}{c}\text { Factor 1 } \\
\text { Shopping } \\
\text { Anxiety }\end{array}$ & $\begin{array}{c}\text { Factor 2 } \\
\text { Irresistible } \\
\text { Spending }\end{array}$ & Communalities & & & Loadings & SMCs & t-values \\
\hline 1 & FO2 & 0.71 & -0.04 & 0.49 & 3.20 & 0.32 & 0.80 & 0.25 & 20.94 \\
\hline 2 & FO6 & 0.70 & 0.09 & 0.54 & 2.75 & 0.40 & 0.81 & 0.37 & 16.28 \\
\hline 3 & FO8 & 0.75 & -0.04 & 0.55 & 3.05 & 0.35 & 0.87 & 0.32 & 18.22 \\
\hline 4 & FO1 & .018 & 0.67 & 0.56 & 3.13 & 0.35 & 0.92 & 0.38 & 11.84 \\
\hline 5 & FO3 & -0.13 & 0.89 & 0.74 & 2.83 & 0.23 & 0.68 & 0.32 & 18.98 \\
\hline \multicolumn{2}{|c|}{ Cumulative Variance Explained } & $37.40 \%$ & $57.90 \%$ & & & & & & \\
\hline \multicolumn{2}{|c|}{ Eigen Value } & 01.87 & 01.02 & & & & & & \\
\hline \multirow{2}{*}{\multicolumn{2}{|c|}{$\begin{array}{l}\text { Factor Correlation } \\
\text { Cronbach's Alpha }(\alpha)\end{array}$}} & 0.25 & & & & & & & \\
\hline \multirow{2}{*}{\multicolumn{2}{|c|}{$\begin{array}{l}\text { Cronbach's Alpha }(\boldsymbol{\alpha}) \\
\text { Overall Scale }(\boldsymbol{\alpha})\end{array}$}} & 0.79 & 0.71 & & & & & & \\
\hline & & & & & & & & & \\
\hline \multicolumn{2}{|c|}{ Composite Reliability (CR) } & 0.80 & 0.69 & & & & & & \\
\hline \multicolumn{2}{|c|}{ Overall Scale (CR) } & & & & & & & & \\
\hline \multirow{2}{*}{\multicolumn{2}{|c|}{ Average Variance Extracted (AVE) }} & 0.53 & 0.48 & & & & & & \\
\hline & & & & & & & & & \\
\hline
\end{tabular}

For factorial validity of the model, we conducted CFA on five items of Revised-TCS with sample A2 $(\mathrm{N}=702)$. A two factor reflective measurement model, Factor 1 (Shopping Anxiety = three items) and Factor 2 (Irresistible spending= two items) was specified which provided good fit to the data $(\mathrm{CMIN} / \mathrm{Df}=2.81, \mathrm{GFI}=0.99, \mathrm{AGFI}=0.98$, $\mathrm{CFI}=0.99, \mathrm{IFI}=0.97, \mathrm{NFI}=0.98, \mathrm{TLI}=0.97, \mathrm{RMSEA}=0.03$, PClose $=0.795)$. Table 4 displays the CFA statistics for five items of two dimensions. Convergent and discriminant validity statics provide legitimacy to the model (Bagozzi \& Yi, 1988) i.e. for shopping anxiety (Cronbach's Alpha $=0.79, \mathrm{CR}=0.80, \mathrm{AVE}=0.53$ ) and for irresistible spending (Cronbach's Alpha $=0.71, \mathrm{CR}=0.69, \mathrm{AVE}=0.48$ ). We used a second order measurement model to test the extent to which both dimensions have Revised-TCS (Compulsive Buying Behavior) as a common causality (Ridgeway et al., 2008; Maccarrone-Eaglen \& Schofield, 2017). Data provided a substantial fit to the model $(\mathrm{CMIN} / \mathrm{Df}=4.37, \mathrm{GFI}=0.98, \mathrm{AGFI}=0.95, \mathrm{CFI}=0.95, \mathrm{IFI}=0.95, \mathrm{NFI}=0.94$, TLI $=0.90$, RMSEA $=0.07$, PClose $=0.059$ ). Second order factor results revealed that both dimensions have substantial and significant factor loadings with Revised-TCS (Shopping Anxiety=0.92, Irresistible Spending=0.8). The convergent and discriminant validity statics for overall/composite TCS are (Cronbach's Alpha $=0.81, \mathrm{CR}=0.83$, $\mathrm{AVE}=0.56$ ) indicating a valid scale. Based on these findings, Revised-TSC included five items representing two dimensions.

To explore new factor structure for nine items of CBI (with three additional items that the scale developers eliminated during CFA in their study), EFA was conducted with sample A1 (N=708). A one-factor solution provided the first adequate fit to the data $($ Chi-Square $=1.47, \mathrm{df}=2, \mathrm{p}<0.01)$ and accounted for $51 \%$ variance with Eigen Value 2.01. Factor matrix results (Table 6) demonstrate that four items have strong and significant factors loadings. Fair and significant inter-item correlations were found (Table 5) and the Cronbach's alpha for the scale was 0.73 indicating internal consistency of items.

Sukkur IBA Journal of Management and Business - SIJMB | Volume 5 No. 2 July - December 2018 @) Sukkur IBA University 
Table 5: Inter-Item Correlation for CBI

\begin{tabular}{lllll}
\hline & R1A & R2A & R5B & R7B \\
\hline R1A & 1.00 & & & \\
R2A & $0.28^{* *}$ & 1.00 & & \\
R5B & $0.34^{* *}$ & $0.33^{* *}$ & 1.00 & \\
R7B & $0.31^{* *}$ & $0.30^{* *}$ & $0.44^{* *}$ & 1.00 \\
\hline
\end{tabular}

Notes: $* * \mathrm{p}<0.01$, Determinant $=.568$

To test the dimensionality of Revised-CBI, we conducted CFA with sample A2 ( $\mathrm{N}=$ 707) on four items. The model provided an excellent fit to the data $(\mathrm{CMIN} / \mathrm{Df}=.98$, $\mathrm{GFI}=0.99, \mathrm{AGFI}=0.99, \mathrm{CFI}=0.99, \mathrm{IFI}=0.99, \mathrm{NFI}=0.98, \mathrm{TLI}=0.99, \mathrm{RMSEA}=0.00$, PClose $=0.643$ ) with all standardized factor loadings conveniently meeting the required minimum threshold (Table 6). Convergent and discriminant validity statistics (Cronbach's Alpha $=0.73, \mathrm{CR}=0.79, \mathrm{AVE}=0.58$ ) assures the reliability and validity of four items Revised-CBI.

Table 6: Exploratory Factor Analysis (EFA), Confirmatory Factor Analysis (CFA), Reliability and Validity of CBI

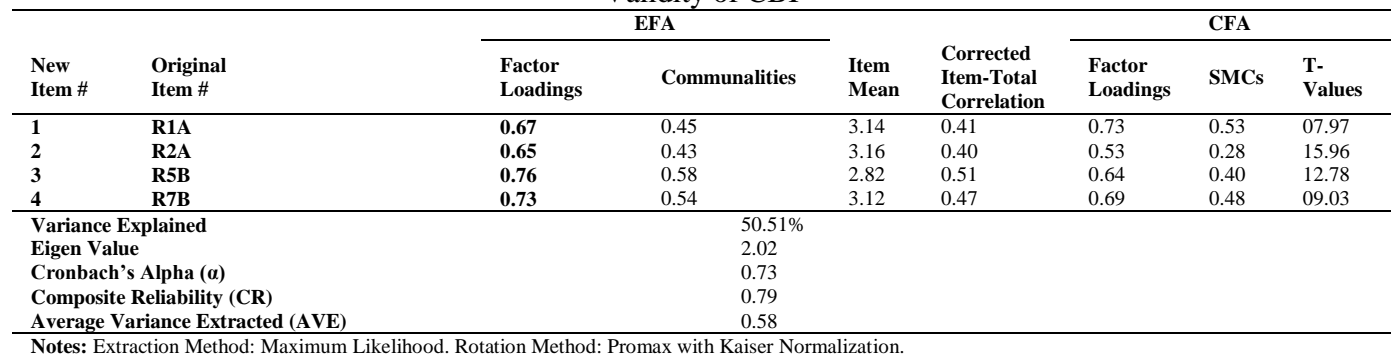

\subsection{Validity and Reliability}

The EFA for TCS and CBI provided the first indication of convergent and discriminant validity. All items for TCS converged massively on their respective factors with significantly high factor loadings (FL > 0.4) indicating convergent validity of RevisedTCS. For Revised-CBI. The factor loadings were also significantly high indicating convergent validity (Leech et al., 2005). Higher communities (h2 > 0.2) among items of Revised-TCS and Revised-CBI indicate higher correlations between items, which is also evidence of convergent validity (Henson \& Roberts, 2006; Childs, 2006). Furthermore, convergent validity is evident from the significant inter-item correlations of both Revised-TCS and Revised-CBI (Tabachnick \& Fidell, 2007; Beavers et al., 2013). The final solutions for Revised-TCS and Revised-CBI had high factor loadings and no cross-loadings, which is an indication of discriminant validity (Tabachnick \& Fidell, 2007). Moreover, the discriminant validity is evident from the correlation between Revised-TCS and Revised-CBI $(r=0.45, \mathrm{p}<0.01)$ which is less than 0.7 (Hair et al., 2013). To further examine the discriminant validity of scales, we calculated Average shared variance (ASV) and Maximum shared variance (MSV). ASV was less

Sukkur IBA Journal of Management and Business - SIJMB | Volume 5 No. 2 July - December 2018 @ Sukkur IBA University 
than MSV and MSV was less than the AVE values for both scales, indicating the discriminant validity of the scales (Hair et al., 2013).

\subsection{Nomological/External Validity}

We assessed the nomological validity of Revised-TCS and Revised-CBI by investigating the relationship of $\mathrm{CBB}$ its correlates such as consumer demographic characteristics, previously identified antecedents and consequences (Hinkins, 1998; Hair et al., 2013; Kline, 2015). We expected Revised-TCS and Revised-CBI to be linked with antecedents and consequences in line with previous findings.

\begin{tabular}{|c|c|c|c|c|c|c|c|c|c|c|c|c|c|c|c|}
\hline$\underline{\text { Sr \# }}$ & Variables & 1 & 2 & 3 & 4 & $4 \mathbf{a}$ & $4 b$ & 5 & 6 & 7 & 8 & 9 & 10 & 11 & 12 \\
\hline 1 & Gender & 1.00 & & & & & & & & & & & & & \\
\hline 2 & Age & -0.02 & 1.00 & & & & & & & & & & & & \\
\hline 3 & Income & -0.06 & $0.42^{* *}$ & 1.00 & & & & & & & & & & & \\
\hline 4 & Revised-TCS & $.006^{*}$ & 0.03 & $-0.08^{*}$ & 1.00 & & & & & & & & & & \\
\hline $4 \mathbf{a}$ & Irresistible Spending & $0.08^{*}$ & 0.01 & $-0.06^{*}$ & $0.82^{* *}$ & 1.00 & & & & & & & & & \\
\hline $4 b$ & Shopping Anxiety & 0.04 & 0.03 & $-0.07^{*}$ & $0.90^{* *}$ & $.051^{* *}$ & 1.00 & & & & & & & & \\
\hline 5 & Revised-CBI & $0.08^{*}$ & 0.03 & -0.06 & $0.45^{* *}$ & $0.31^{* *}$ & $0.45^{* *}$ & 1.00 & & & & & & & \\
\hline 6 & Depression & -0.04 & 0.04 & -0.06 & $0.47^{* *}$ & $0.37^{* *}$ & $0.43^{* *}$ & $0.47^{* *}$ & 1.00 & & & & & & \\
\hline 7 & Materialism & 0.00 & $-0.09^{* *}$ & -0.01 & $0.09^{* *}$ & $0.07^{*}$ & $0.09^{* *}$ & $0.06^{*}$ & $0.28^{* *}$ & 1.00 & & & & & \\
\hline 8 & Anxiety & -0.00 & $0.06^{*}$ & $-0.07^{*}$ & $0.41^{* *}$ & $0.34^{* *}$ & $0.37^{* *}$ & $0.44^{* *}$ & $0.78^{* *}$ & $-0.29^{* *}$ & 1.00 & & & & \\
\hline 9 & Stress & -0.03 & 0.05 & $-0.07^{*}$ & $0.48^{* *}$ & $0.39^{* *}$ & $0.44^{* *}$ & $0.49^{* *}$ & $0.83^{* *}$ & $-0.30^{* *}$ & $0.84^{* *}$ & 1.00 & & & \\
\hline 10 & Self Esteem & 0.05 & -0.04 & $0.09^{* *}$ & $-0.54^{* *}$ & $-0.44^{* *}$ & $-0.49^{* *}$ & $-0.51^{* *}$ & $-0.86^{* *}$ & $0.24^{* *}$ & $-0.79^{* *}$ & $-0.83^{* *}$ & 1.00 & & \\
\hline 11 & Positive Feelings & 0.03 & 0.01 & $-0.10^{* *}$ & $0.40^{* * *}$ & $0.33^{* *}$ & $0.37^{* *}$ & $0.40^{* *}$ & $0.75^{* *}$ & $-0.28^{* *}$ & $0.77^{* *}$ & $0.80^{* *}$ & $-0.77^{* *}$ & 1.00 & \\
\hline 12 & Hiding Behavior & $-0.07^{*}$ & 0.05 & -0.05 & $0.38^{* *}$ & $0.29^{* *}$ & $0.36^{* *}$ & $0.40^{* *}$ & $0.63^{* *}$ & $-0.17^{* *}$ & $0.58^{* *}$ & $0.65^{* *}$ & $-0.60^{* *}$ & $0.53^{* *}$ & 1.00 \\
\hline
\end{tabular}

Correlation results (See Table 7) indicate that Revised-TCS and Revised-CBI significantly correlated with gender. This confirmed that women are more compulsive than men. Age is related to neither Revised-TCS nor Revised-CBI. Revised-TCS significantly correlated with income but the correlation was very weak, whereas Revised-CBI did not correlate with income. Revised-TCS is associated with income as it has two items indicative of unavailability of sufficient resources, but Revised-CBI is independent of income.

Reliability and validity statistics for depression $(\alpha=0.81, \mathrm{CR}=0.89, \mathrm{AVE}=0.61)$, anxiety $(\alpha=0.87, \mathrm{CR}=0.90, \mathrm{AVE}=0.69)$ and stress $(\alpha=0.84, \mathrm{CR}=0.8, \mathrm{AVE}=0.52)$ indicated validity of measures. Depression, anxiety and stress were positively and significantly correlated with Revised-TCS and Revised-CBI as expected. In structural analysis, depression anxiety and stress significantly influenced Revised-TCS ( $y$ Dep $=$ $0.24, \mathrm{p}<0.01 ;$ y Anx $=0.33, \mathrm{p}<0.01$; y Stress $=0.79, \mathrm{p}<0.01)$ and Revised-CBI ( $y$ Dep $=0.27, \mathrm{p}<0.01 ; y \mathrm{Anx}=0.37, \mathrm{p}<0.01 ; y$ Stress $=0.81, \mathrm{p}<0.01)$.The materialism scale yielded satisfactory reliability and validity $(\alpha=0.9, \mathrm{CR}=0.89, \mathrm{AVE}=0.61)$. Although weak, a positive correlation was found between materialism and RevisedTCS and Revised-CBI. Materialism also significantly influenced Revised-TCS ( $y=$ $0.05, \mathrm{p}<0.01)$ and Revised-CBI $(y=0.03, \mathrm{p}<0.01)$ in structural analysis. In line with previous findings, results suggested that materialistic consumers are more likely to exhibit compulsive buying tendencies. Self-esteem scale showed strong reliability and

Sukkur IBA Journal of Management and Business - SIJMB | Volume 5 No. 2 July - December 2018 @ Sukkur IBA University 
validity $(\alpha=0.71, \mathrm{CR}=0.73, \mathrm{AVE}=0.5)$ and a negative correlation was found between self-esteem and both Revised-TCS and Revised-CBI. As expected, self-esteem also negatively influenced Revised-TCS $(y=-0.48, \mathrm{p}<0.01)$ and Revised-CBI $(y=-0.40$, $\mathrm{p}<0.01)$. Results complement previous findings that lesser the self-esteem of consumers, higher would be their compulsive buying tendencies.

Table 8.: Results of Regression Analysis

\begin{tabular}{|c|c|c|c|c|c|c|c|c|c|c|}
\hline \multirow{2}{*}{\multicolumn{3}{|c|}{ Structural Paths }} & \multicolumn{4}{|c|}{ Revised-TCS } & \multicolumn{4}{|c|}{ Revised-CBI } \\
\hline & & & \multirow{2}{*}{$\frac{\boldsymbol{y}}{0.24}$} & \multirow{2}{*}{$\begin{array}{l}\text { S.E. } \\
0.01\end{array}$} & \multirow{2}{*}{$\frac{\text { t-values }}{4.09}$} & \multirow{2}{*}{$\frac{\text { p-values }}{* * *}$} & \multirow{2}{*}{$\frac{\boldsymbol{y}}{0.27}$} & \multirow{2}{*}{$\begin{array}{l}\text { S.E. } \\
0.02\end{array}$} & \multirow{2}{*}{$\frac{\text { t-values }}{5.64}$} & \multirow{2}{*}{$\frac{\text { p-values }}{* * *}$} \\
\hline Depression & $\rightarrow$ & Revised-TCS/CBI & & & & & & & & \\
\hline Materialism & $\rightarrow$ & Revised-TCS/CBI & 0.05 & 0.00 & 2.93 & 0.00 & 0.03 & 0.01 & 2.23 & 0.01 \\
\hline Anxiety & $\rightarrow$ & Revised-TCS/CBI & 0.33 & 0.01 & 4.29 & $* * *$ & 0.37 & 0.01 & 6.04 & $* * *$ \\
\hline Stress & $\rightarrow$ & Revised-TCS/CBI & 0.79 & 0.03 & 4.61 & $* * *$ & 0.81 & 0.03 & 6.82 & $* * *$ \\
\hline Self Esteem & $\rightarrow$ & Revised-TCS/CBI & -0.48 & 0.03 & -4.51 & $* * *$ & -0.40 & 0.02 & 6.32 & $* * *$ \\
\hline Revised-TCS/CBI & $\rightarrow$ & Positive Feelings & 0.90 & 0.56 & 4.47 & $* * *$ & 0.90 & 0.26 & 6.38 & $* * *$ \\
\hline Revised-TCS/CBI & $\rightarrow$ & Hiding Behavior & 0.45 & 0.45 & 4.44 & $* * *$ & 0.45 & 0.21 & 6.29 & $* * *$ \\
\hline
\end{tabular}

Positive feelings exhibited satisfactory reliability and validity $(\alpha=0.77, \mathrm{CR}=0.75$, AVE $=0.51$ ). Both Revised-TCS and Revised-CBI positively correlated with positive feelings. TCS and CBI as predictors, have significant influence on positive feelings $(y$ TCS $=0.90, p<0.01 ; y \mathrm{CBI}=0.90, \mathrm{p}<0.01)$ indicating that compulsive consumers experience momentary positive feelings from the buying process. Hiding behavior provided excellent reliability and validity $(\alpha=0.83, \mathrm{CR}=0.81, \mathrm{AVE}=0.64)$. Both Revised-TCS and Revised-CBI has positive correlation with hiding behavior and both significantly influenced hiding behavior $(y \mathrm{TCS}=0.45, \mathrm{p}<0.01$; y CBI $=0.45, \mathrm{p}<$ 0.01). This indicates that compulsive buyers tend to hide their purchases and buying habits.

\subsection{Prevalence Estimates}

We estimated the current prevalence of compulsive buying behavior in shopping malls (Sample A $=2820$ ) and university students (Sample B = 985), to identify consumers who suffer from compulsive buying disorder. Unlike previous studies, we employed newly developed universal cut off point criteria that classifies consumers into multiple categories on a continuum according to their level of compulsiveness (Edwards, 1993; Albanese, 1988; Moon \& Attiq, 2018). This continuum draws a parallel between compulsive and addictive buying to identify varying levels of compulsiveness. These levels are presented in the following tables.

Table 9: Prevalence Estimates for Revised-TCS

\begin{tabular}{|c|c|c|c|c|c|c|c|c|c|c|c|c|c|c|}
\hline \multirow[b]{2}{*}{$\mathrm{Sr} \#$} & \multirow[b]{2}{*}{ Classification } & \multirow[b]{2}{*}{ Mean Score } & \multicolumn{6}{|c|}{ Shopping Mall Consumers (Sample A) } & \multicolumn{6}{|c|}{ University Student (Sample B) } \\
\hline & & & $\begin{array}{l}\text { Male } \\
862\end{array}$ & & $\begin{array}{l}\text { Fema } \\
543\end{array}$ & & $\begin{array}{l}\text { Total } \\
1405\end{array}$ & & $\begin{array}{l}\text { Male } \\
447\end{array}$ & & $\begin{array}{l}\text { Fema } \\
448\end{array}$ & & $\begin{array}{l}\text { Tota } \\
895\end{array}$ & \\
\hline & & & $\mathrm{N}$ & $\%$ & $\mathrm{~N}$ & $\%$ & $\mathrm{~N}$ & $\%$ & $\mathrm{~N}$ & $\%$ & $\mathrm{~N}$ & $\%$ & $\mathrm{~N}$ & $\%$ \\
\hline 1 & Normal & 1 & 12 & 40 & 18 & 60 & 30 & 2.14 & 13 & 76.5 & 4 & 23.5 & 17 & 1.89 \\
\hline 2 & Recreational & $1.1-2$ & 180 & 59.6 & 122 & 40.4 & 302 & 21.5 & 110 & 52.6 & 99 & 47.4 & 209 & 23.4 \\
\hline 3 & Borderline & $2.1-3$ & 332 & 64.1 & 186 & 35.9 & 518 & 36.9 & 196 & 50.8 & 192 & 49.2 & 388 & 43.4 \\
\hline 4 & Compulsive & $3.1-4$ & 257 & 62.8 & 152 & 37.2 & 409 & 29.1 & 119 & 46.8 & 135 & 53.1 & 254 & 28.3 \\
\hline 5 & Addictive & $4.1-5$ & 81 & 55.5 & 65 & 44.5 & 146 & 10.4 & 9 & 33.3 & 18 & 66.5 & 27 & 3.02 \\
\hline
\end{tabular}

Sukkur IBA Journal of Management and Business - SIJMB | Volume 5 No. 2 July - December 2018 @ Sukkur IBA University 106 
The Revised-TCS (Table 9) identified 29.1\% ( $=409)$ compulsive buyers in sample A $(\mathrm{N}=1405)$ and $28.3 \%(\mathrm{~N}=254)$ compulsive buyers in sample $\mathrm{B}(\mathrm{N}=895)$. In both samples $\mathrm{A}$ and $\mathrm{B}$, more women $37.2 \%(\mathrm{~N}=152)$ and $53.1 \%(\mathrm{~N}=135)$ are classified as compulsive buyers. A higher percentage of around $40 \%$ of consumers were borderline compulsive buyers in both samples. The Revised-CBI (Table 10) successfully classified $33.8 \%(\mathrm{~N}=479)$ consumers as compulsive buyers in Sample A (shopping mall consumers). In Sample B (university students) it categorized $29.7 \%$ (N $=264$ ) consumers as compulsive. Like the Revised-TCS, Revised-CBI also identified more women as compulsive buyers compared to men in both samples.

Table 10: Prevalence Estimates for Revised-CBI

\begin{tabular}{|c|c|c|c|c|c|c|c|c|c|c|c|c|c|c|}
\hline \multirow{3}{*}{$\mathrm{Sr} \#$} & \multirow[b]{2}{*}{ Classification } & \multirow[b]{2}{*}{ Mean Score } & \multicolumn{6}{|c|}{ Shopping Mall Consumers (Sample A) } & \multicolumn{6}{|c|}{ University Student (Sample B) } \\
\hline & & & $\begin{array}{l}\text { Male } \\
872\end{array}$ & & $\begin{array}{l}\text { Fema } \\
543\end{array}$ & & $\begin{array}{l}\text { Total } \\
1415\end{array}$ & & $\begin{array}{l}\text { Male } \\
447\end{array}$ & & $\begin{array}{l}\text { Femal } \\
448\end{array}$ & & $\begin{array}{l}\text { Total } \\
895\end{array}$ & \\
\hline & & & $\mathrm{N}$ & $\%$ & $\mathrm{~N}$ & $\%$ & $\mathrm{~N}$ & $\%$ & $\mathrm{~N}$ & $\%$ & $\mathrm{~N}$ & $\%$ & $\mathrm{~N}$ & $\%$ \\
\hline 1 & Normal & 1 & 72 & 64.3 & 40 & 35.7 & 112 & 7.9 & 16 & 66.7 & 8 & 33.3 & 24 & 2.7 \\
\hline 2 & Recreational & $1.1-2$ & 156 & 62.2 & 95 & 37.9 & 251 & 17.7 & 110 & 58.5 & 78 & 41.5 & 188 & 21 \\
\hline 3 & Borderline & $2.1-3$ & 250 & 57.5 & 185 & 42.5 & 435 & 30.7 & 176 & 49.4 & 180 & 50.6 & 356 & 39.8 \\
\hline 4 & Compulsive & $3.1-4$ & 280 & 58.5 & 199 & 41.5 & 479 & 33.8 & 115 & 43.6 & 149 & 56.4 & 264 & 29.5 \\
\hline 5 & Addictive & $4.1-5$ & 114 & 82.4 & 24 & 17.4 & 138 & 9.7 & 30 & 47.6 & 33 & 52.4 & 63 & 7 \\
\hline
\end{tabular}

\section{Discussion and Implications}

In the present study, we tested the validity of original TSC and CBI, developed to measure CBB. The originally proposed factor structures for TCS and CBI could not be validated because American and Pakistani samples may interpret scales differently (Tommasi \& Busonera, 2012). Hence, we explored new factor structures for both TCS and CBI. Consequently, we found a new two-factor structure for Revised-TSC and onefactor structure for Revised-CBI. Two dimensions of Revised-TCS, shopping anxiety, and irresistible spending contained items signifying restlessness that is associated with shopping and the compulsion to spend on undesired things respectively. Revised-TCS does not include items that relate to income that has been a significant point of criticism over the years (Ridgway et al., 2008; Tommasi \& Busonera, 2012; Maraz et al., 2018). Furthermore, we developed a new classification scheme based on consumer's level compulsiveness on a continuum that ranges across the categories; normal/ non compulsive consumer (consumer, buying mainly out of necessity), recreational consumer (consumer who use buying occasionally to relieve stress), borderline compulsive consumers (somewhere in between compulsive and recreational buying tendencies), compulsive consumers (buy mostly to relieve anxiety) and addictive consumers (extreme buyers who suffer dysfunctions in life due to their buying). Since compulsive buying is believed to be a behavioral addiction (e.g., Maraz, Griffiths \& Demetrovics, 2016; Davenport et al., 2012), we consider this classification more valid and relevant. Unlike previous dichotomous classification schemes, this scheme broadens our understanding of the levels of consumer's compulsiveness.

Sukkur IBA Journal of Management and Business - SIJMB | Volume 5 No. 2 July - December 2018 @ Sukkur IBA University 
We also estimated the prevalence rate of compulsive buying behavior in shopping mall consumers and university students. On both scales, shopping mall consumers showed higher prevalence estimates (Revised-TCS $=29 \%$, Revised-CBI $=34 \%$ ) as compared to the prevalence rates estimated in university students (Revised-TCS $=28 \%$, Revised$\mathrm{CBI}=29 \%$ ). The findings are consistent with previous findings where consumers in shopping mall exhibited greater average compulsive tendencies as compared to any other sample (Weinstein et al., 2016; Moon \& Attiq, 2018). The differences in prevalence rates calculated by both Revised-TCS and Revised-CBI are minimal, unlike previous findings where different instruments yield hugely different prevalence estimates (Maraz et al., 2016). This may be attributed to the theoretical, methodological, and cultural adjustments made in both Revised-TCS and Revised-CBI. For instance, both revised scales use the same cutoff points, classification scheme, and both measure current prevalence. Negligible differences that remain in prevalence estimates may be because of the sample, demographic, situational and personality differences but overall revised scales performed excellently. Both revised scales identified more women as compulsive buyers in both shopping mall consumers and university students.

Though the strength of the linear relationship was not very strong for either of the scales with gender, the findings still compliment the previous findings where women are more likely to be compulsive buyers (Neuner et al., 2005; Mueller et al., 2010; Otero-López \& Villardefrancos, 2013; Orth, Robins \& Widaman, 2012). Only Revised-TCS showed a significant relationship with income because some items of the scale discuss resources for buying things. Revised-CBI did not correlate with income that supports that compulsive buying is not an income dependent behavior and this argument is more relevant to the definitions of compulsive buying (Maraz et al., 2016; Otero-López \& Villardefrancos, 2013). As far as the antecedents and consequences are concerned, both Revised-TCS and Revised-CBI correlated in theoretically hypnotized directions that signifies the external validity of the scales. Taken together, Revised-CBI performed marginally better with both samples in relation to estimating prevalence, correlation with demographics, antecedents and consequences, reliability and validity estimates and theoretical relevance.

\section{Conclusion}

$\mathrm{CBB}$ is a pathological consumer behavior that has severe harmful consequences for not only an individual but also for society. With the introduction of consumer culture in emerging economies, it has become a point of concern in such economies. This study aimed at validating two most widely used compulsive buying scales TCS and CBI and developing a new universal cutoff point classification for these scales. The theoretical, methodological and cultural adjustments along with employment of a universal and comprehensive classification scheme, lead us to refined compulsive buying scales that are more relevant to population and culture in developing economies.

Sukkur IBA Journal of Management and Business - SIJMB | Volume 5 No. 2 July - December 2018 @ Sukkur IBA University 


\section{Limitations and Future Research}

Although this study has many strongholds, we acknowledge various limitations. First, the study was limited to shopping mall consumers and university students; future researches may include consumers from other fields of life, in particular, more representative general population. Second, we collected data only from fashion clothing consumers. Future studies may include other product categories for better generalizability of results. We only validated the two most widely used scales, whereas various other scales are also used to measure CBB. Future studies should also validate those scales in cultures other than the U.S. and developing economies. This study does not compare and contrast these scales directly to each other; therefore; this issue may be taken up in future researches. The classification scheme may also be used in future studies to understand compulsive buying in greater detail. The Revised TCS and CBI should be used in future studies for further psychometric validation.

\section{References:}

American Psychiatric Association. (2013). Diagnostic and statistical manual of mental disorders (DSM-5®).(5th ed.). Washington, DC American Psychiatric Pub.

Achtziger, A., Hubert, M., Kenning, P., Raab, G., \& Reisch, L. (2015). Debt out of control: The links between self-control, compulsive buying, and real debts. Journal of Economic Psychology, 49, 141-149.

Albanese, P. J. (1988). The intimate relations of the consistent consumer: Psychoanalytic object relations theory applied to economics. Psychological foundations of economic behavior, 59-79.

Anderson, J. C., \& Gerbing, D. W. (1988). Structural equation modeling in practice: A review and recommended two-step approach. Psychological Bulletin, 103(3), 411.

Bagozzi, R. P., \& Yi, Y. (1988). On the evaluation of structural equation models. Journal of the academy of marketing science, 16(1), 74-94.

Baker, A. M., Moschis, G. P., Rigdon, E. E., \& Fatt, C. K. (2016). Linking family structure to impulse-control and obsessive-compulsive buying. Journal of Consumer Behaviour, 15(4), 291-302.

Baum, A. (1990). Stress, intrusive imagery, and chronic distress. Health Psychology, 9(6), 653.

Beavers, A. S., Lounsbury, J. W., Richards, J. K., Huck, S. W., Skolits, G. J., \& Esquivel, S. L. (2013). Practical considerations for using exploratory factor analysis in educational research. Practical assessment, research \& evaluation, 18(6), 1-13.

Bittner, A., Goodwin, R. D., Wittchen, H. U., Beesdo, K., Höfler, M., \& Lieb, R. (2004). What characteristics of primary anxiety disorders predict subsequent major depressive disorder?. The Journal of clinical psychiatry. 65(5), 618-626

Sukkur IBA Journal of Management and Business - SIJMB | Volume 5 No. 2 July - December 2018 @ Sukkur IBA University 
Black, D. W., Shaw, M., McCormick, B., Bayless, J. D., \& Allen, J. (2012). Neuropsychological performance, impulsivity, ADHD symptoms, and novelty seeking in compulsive buying disorder. Psychiatry Research, 200(2), 581-587.

Byrne, B. M. (2013). Structural equation modeling with Mplus: Basic concepts, applications, and programming. Routledge.

Childs, D. (2006). Britain since 1945: A political history. Taylor \& Francis.

Costello, A. B., \& Osborne, J. W. (2005). Best practices in exploratory factor analysis: Four recommendations for getting the most from your analysis. Practical assessment, research \& evaluation, 10(7), 1-9.

Davenport, K., Houston, J. E., \& Griffiths, M. D. (2012). Excessive eating and compulsive buying behaviors in women: An empirical pilot study examining reward sensitivity, anxiety, impulsivity, self-esteem and social desirability. International Journal of Mental Health and Addiction, 10(4), 474489.

Edwards, E. A. (1993). Development of a new scale for measuring compulsive buying behavior. Financial counseling and planning, 4(1), 67-84.

Faber, R. J., \& O'guinn, T. C. (1992). A clinical screener for compulsive buying. Journal of Consumer Research, 19(3), 459-469.

Fornell, C., \& Larcker, D. (1987). A second generation of multivariate analysis: Classification of methods and implications for marketing research. Review of Marketing, 1, 407-450.

Gallagher, C. E., Watt, M. C., Weaver, A. D., \& Murphy, K. A. (2017). "I fear, therefore, I shop!" exploring anxiety sensitivity in relation to compulsive buying. Personality and Individual Differences, 104, 37-42.

Grougiou, V., Moschis, G., \& Kapoutsis, I. (2015). Compulsive buying: the role of earlier-in-life events and experiences. Journal of Consumer Marketing, 32(4), 278-289.

Guo, Z., \& Cai, Y. (2011). Exploring the antecedents of compulsive buying tendency among adolescents in China and Thailand: a consumer socialization perspective. African Journal of Business Management, 5(24), 10198.

Hair, J. F., Ringle, C. M., \& Sarstedt, M. (2013). Partial least squares structural equation modeling: Rigorous applications, better results and higher acceptance. Long Range Planning, 46(1-2), 1-12.

Henson, R. K., \& Roberts, J. K. (2006). Use of exploratory factor analysis in published research: Common errors and some comment on improved practice. Educational and Psychological Measurement, 66(3), 393-416.

Hinkin, T. R. (1998). A brief tutorial on the development of measures for use in survey questionnaires. Organizational research methods, 1(1), 104-121.

Hollander, E., \& Allen, A. (2006). Is compulsive buying a real disorder, and is it really compulsive?. American Journal of Psychiatry, 163 (10), 1670-72

Sukkur IBA Journal of Management and Business - SIJMB | Volume 5 No. 2 July - December 2018 @ Sukkur IBA University 
Horváth, C., Adigüzel, F., \& Herk, H. V. (2013). Cultural aspects of compulsive buying in emerging and developed economies: a cross-cultural study in compulsive buying. Organizations and Markets In Emerging Economies. 4 (2). 8-24.

Kline, R. B. (2015). Principles and practice of structural equation modeling. Guilford publications.

Kukar-Kinney, M., Scheinbaum, A. C., \& Schaefers, T. (2016). Compulsive buying in online daily deal settings: An investigation of motivations and contextual elements. Journal of business research, 69(2), 691-699.

Kwak, H., Zinkhan, G. M., \& Crask, M. R. (2003). Diagnostic screener for compulsive buying: Applications to the USA and South Korea. Journal of Consumer Affairs, 37(1), 161-169.

Leech, N. L., Barrett, K. C., \& Morgan, G. A. (2005). SPSS for intermediate statistics: Use and interpretation. Psychology Press.

Lejoyeux, M., Mathieu, K., Embouazza, H., Huet, F., \& Lequen, V. (2007). Prevalence of compulsive buying among customers of a Parisian general store. Comprehensive Psychiatry, 48(1), 42-46.

Lovibond, P. F., \& Lovibond, S. H. (1995). The structure of negative emotional states: Comparison of the Depression Anxiety Stress Scales (DASS) with the Beck Depression and Anxiety Inventories. Behavior research and therapy, 33(3), 335-343.

Maccarrone-Eaglen, A., \& Schofield, P. (2017). Compulsive buying behavior: Reevaluating its dimensions and screening. Journal of Consumer Behavior. 16(5), 463-473.

Maraz, A., Eisinger, A., Hende, B., Urbán, R., Paksi, B., Kun, B., ... \& Demetrovics, Z. (2015). Measuring compulsive buying behavior: psychometric validity of three different scales and prevalence in the general population and in shopping centers. Psychiatry Research, 225(3), 326-334.

Maraz, A., Griffiths, M. D., \& Demetrovics, Z. (2016). The prevalence of compulsive buying: a meta-analysis. Addiction, 111(3), 408-419.

McElroy, S. L., Keck, P. E., Jr., Pope, H. G., Jr., Smith, J. M. R., \& Srakowski, S. M. (1994). Compulsive buying: a report of 20 cases. Journal of Clinical Psychiatry, 55, 242-248.

Moon, M. A., \& Attiq, S. (2018). Compulsive buying behavior: antecedents, consequences and prevalence in shopping mall consumers of an emerging economy. Pakistan Journal of Commerce and Social Sciences (PJCSS), 12(2), 548-570.

Moon, M. A., Javaid, B., Kiran, M., Awan, H. M., \& Farooq, A. (2018). Consumer perceptions of counterfeit clothing and apparel products attributes. Marketing Intelligence \& Planning, 36(7), 794-808.

Mueller, A., Mitchell, J. E., Crosby, R. D., Gefeller, O., Faber, R. J., Martin, A., ... \& de Zwaan, M. (2010). Estimated prevalence of compulsive buying in Germany

Sukkur IBA Journal of Management and Business - SIJMB | Volume 5 No. 2 July - December 2018 @ Sukkur IBA University 
and its association with sociodemographic characteristics and depressive symptoms. Psychiatry research, 180(2), 137-142.

Neuner, M., Raab, G., \& Reisch, L. A. (2005). Compulsive buying in maturing consumer societies: An empirical re-inquiry. Journal of economic psychology, 26(4), 509-522.

Orth, U., Robins, R. W., \& Widaman, K. F. (2012). Life-span development of selfesteem and its effects on important life outcomes. Journal of personality and social psychology, 102(6), 1271-1288.

Otero-López, J. M., \& Pol, E. V. (2013). Compulsive buying and the Five-Factor Model of personality: A facet analysis. Personality and Individual Differences, 55(5), 585-590.

Otero-López, J. M., \& Villardefrancos, E. (2013). Materialism and addictive buying in women: the mediating role of anxiety and depression. Psychological Reports, 113(1), 328-344.

Richins, M. L. (2004). The material values scale: Measurement properties and development of a short form. Journal of Consumer Research, 31(1), 209-219.

Ridgway, N. M., Kukar-Kinney, M., \& Monroe, K. B. (2008). An expanded conceptualization and a new measure of compulsive buying. Journal of Consumer Research, 35(4), 622-639.

Roberts, J. A., \& Sepulveda M, C. J. (1999). Money attitudes and compulsive buying: an exploratory investigation of the emerging consumer culture in Mexico. Journal of International Consumer Marketing, 11(4), 53-74.

Roberts, J. A., Manolis, C., \& Pulling, C. (2014). Contingent self-esteem, selfpresentational concerns, and compulsive buying. Psychology and Marketing, 31(2), 147-160.

Rosenberg, Morris (1965), Society and the Adolescent Self-Image, Princeton, NJ: Princeton University Press.

Suhr, D. D. (2006). Exploratory or confirmatory factor analysis? (pp. 1-17). Cary: SAS Institute.

Tabachnick, B. G., \& Fidell, L. S. (2007). Experimental designs using ANOVA. Thomson/Brooks/Cole.

Tommasi, M., \& Busonera, A. (2012). Validation of three compulsive buying scales on an Italian sample. Psychological Reports, 111(3), 831-844.

Villella, C., Martinotti, G., Di Nicola, M., Cassano, M., La Torre, G., Gliubizzi, M. D., ... \& Conte, G. (2011). Behavioral addictions in adolescents and young adults: results from a prevalence study. Journal of Gambling Studies, 27(2), 203-214.

Weinstein, A., Maraz, A., Griffiths, M. D., Lejoyeux, M., \& Demetrovics, Z. (2016). Compulsive Buying-Features and Characteristics of Addiction. In Neuropathology

Drug Addictions and Substance Misuse (pp. 993-1007).

Sukkur IBA Journal of Management and Business - SIJMB | Volume 5 No. 2 July - December 2018 @ Sukkur IBA University 
Moon et al. Psychometric Validation and Prevalence of Compulsive Buying Behavior in an Emerging

Economy

(рp. 92-113)

Zhao, H., Tian, W., \& Xin, T. (2017). The Development and Validation of the Online Shopping Addiction Scale. Frontiers in psychology, 8, 735. 10.3389/fpsyg.2017.00735

Sukkur IBA Journal of Management and Business - SIJMB | Volume 5 No. 2 July - December 2018 @ Sukkur IBA University 113 